\title{
Circulating Immune Complexes in Cutaneous Vasculitis
}

\author{
DETECTION WITH Clq AND MONOCLONAL RHEUMATOID FACTOR
}

\author{
Susan E. Mackel, Gerhard Tappeiner, Hilton Brumfield, and \\ Robert E. JoRDON, Cutaneous Immunopathology Unit, Research Service, \\ Veterans Administration Center, Wood (Milwaukee), Wisconsin 53193; \\ Dermatology Section, Department of Medicine, Medical College \\ of Wisconsin, Milwaukee, Wisconsin; Department of Dermatology, \\ University of Innsbruck, Austria
}

\begin{abstract}
A в S T R A C T To investigate the pathogeneic significance of immune complexes in cutaneous vasculitis, 107 patients with various forms of cutaneous vasculitis, including 59 patients with necrotizing (leukocytoclastic) vasculitis (group 1), and 48 patients with lymphocytic vasculitis, or a predominately lymphocytic perivascular infiltrate (group 2), were studied. Immunoglobulins or complement components in cutaneous blood vessels were detected by direct immunofluorescence in high frequency in both groups $(91$ and $88 \%$, respectively). Using two radioassays for circulating immune complexes, $\mathrm{Clq}$ or monoclonal rheumatoid factor $(\mathrm{mRF})$ reactive material was detected in $68 \%$ of the patients with necrotizing vasculitis but only $44 \%$ of the patients in the lymphocytic-perivascular group. The mRF radioassay was elevated in $58 \%$ of the first group of patients and $41 \%$ of the patients in group 2 , although $\mathrm{Clq}$ binding activity was increased in $54 \%$ of the patients with necrotizing vasculitis but only in $9 \%$ of the patients with a lymphocytic vasculitis or lymphocytic perivascular infiltrate. By using both sucrose density gradient ultracentrifugation and Sepharose $6 \mathrm{~B}$ gel filtration, the $\mathrm{Clq}$ and $\mathrm{mRF}$ reactive material detected in some patients with necrotizing vasculitis eluted in high molecular weight fractions that were also anticomplementary. In one patient with necrotizing vasculitis and hepatitis $B$ antigenemia, these heavy molecular weight $\mathrm{Clq}$ and $\mathrm{mRF}$ reactive fractions contained a two- to three-fold increase in hepatitis
\end{abstract}

Presented in part at the Annual Meeting of the American Federation for Clinical Research, 30 April 1978, San Francisco, Calif.

Dr. Mackel is a recipient of U. S. Public Health Service Fellowship 1F32 AM0637-01. Dr. Jordon is a recipient of a Medical Career Investigatorship of the Veterans Administration.

Received for publication 26 March 1979 and in revised form 19 July 1979.
B surface antigen when compared with lighter molecular weight fractions. Heavy and light molecular weight $\mathrm{mRF}$ reactive material could be detected in selected patients in the lymphocytic-perivascular group as well as in the necrotizing vasculitis group. These studies suggest that cutaneous vasculitis, including acute necrotizing (leukocytoclastic) vasculitis and some forms of lymphocytic vasculitis, and perhaps some diseases characterized by a lymphocytic perivascular infiltrate, may represent cutaneous expressions of immune complex disease.

\section{INTRODUCTION}

Cutaneous necrotizing vasculitis is an inflammatory disease of dermal blood vessels that presents clinically as palpable purpura located primarily on the lower extremities $(1,2)$. Histologically, the hallmark of this disease is an infiltration of blood vessels by polymorphonuclear leukocytes resulting in a fibrinoid necrosis of the vessel walls with endothelial cell swelling, extravasation of erythrocytes, and leukocytoclasis (3-5). Although immunopathogenic mechanisms have been postulated for this disease, the evidence to substantiate this theory is still inconclusive.

The histologic changes seen in necrotizing vasculitis resemble those found in necrotic lesions produced by the Arthus phenomenon (6), a localized antigen-antibody reaction (7). Direct immunofluorescence (IF) ${ }^{1}$ of skin biopsy specimens often shows the deposition of immunoglobulins, complement components, and fibrin in the walls of affected blood vessels $(6,8-11)$. These observations and the demonstration of anticomple-

${ }^{1}$ Abbreviations used in this paper: Agg, heat-aggregated; $\mathrm{BA}$, binding activity; $\mathrm{CH}_{50}$, hemolytic complement; $\mathrm{HB}_{\mathrm{s}} \mathrm{Ag}$, hepatitis $B$ surface antigen; IF, immunofluorescence; mRF, monoclonal rheumatoid factor; RF, rheumatoid factor. 
mentary activity $(12-14)$ in the sera of some patients have led to the hypothesis that necrotizing vasculitis represents a cutaneous expression of immune complex disease. This theory is supported clinically by the increased frequency of both hypocomplementemia (1518 ) and cryoglobulinemia $(12-14,19)$ in these patients as well as an increased occurrence of various forms of cutaneous vasculitis in patients with known immune complex-associated diseases, for example, systemic lupus erythematosus. Further, Braverman et al. (20) have demonstrated the existence of electron dense material in the blood vessels of histamine-induced lesions in patients with active necrotizing vasculitis before infiltration of polymorphonuclear cells; deposits that corresponded to deposition of immunoglobulin and C3 detected by direct IF.

Despite the fact that circulating immune complexes with subsequent deposition in cutaneous vessels has been postulated as the pathogenetic mechanism in necrotizing vasculitis, few reports have appeared in the literature to document this basic hypothesis. In an attempt to add support to the theory of an immune complex-related pathogenesis, serum samples from 107 patients with various forms of cutaneous vasculitis, including 59 patients with cutaneous necrotizing (leukocytoclastic) vasculitis were tested for the presence of circulating immune complexes using both $\mathrm{Clq}$ binding and monoclonal rheumatoid factor (mRF) inhibition radioassays. Patients with a lymphocytic vasculitis and patients who demonstrated primarily a lymphocytic perivascular infiltrate were included in the study as a group for comparison with patients with necrotizing vasculitis. To characterize the reactive material present in the sera as immune complexes, density gradient ultracentrifugation and gel filtration chromatography techniques were performed on selected samples. Fractions were then tested for the presence of immune complexes by both radioassays, a standard anticomplementary assay, and by double immunodiffusion.

\section{METHODS}

Reagents. Reagents used in this study included: Sepharose 6B, Sephadex G-25, and Sephadex G-200 (Pharmacia Fine Chemicals, Uppsala, Sweden) antibodies to immunoglobulin (Ig)G, IgM, IgA, C3 and fibrin (Meloy Laboratories, Inc., Springfield, Va.); IgG Cohn fraction II (Research Products Division, Miles Laboratories, Inc., Elkhart, Ind.); disodium ethylenediamine-tetraacetate (EDTA), ACS certified sucrose (Fisher Scientific Co., Pittsburgh, Pa.); CnBr (Eastman Kodak Co., Rochester, N. Y.); polyethylene glycol 6000, agarose, lactoperoxidase (Sigma Chemical Co., St. Louis, Mo.); avicel microcystalline cellulose (Brinkmann Instruments, Inc., Westbury, N. Y.); DNA and DNase I (Worthington Biochemical Corp., Freehold, N. J.) and ${ }^{125}$ I (New England Nuclear, Boston, Mass.).

Patient selection. The patients in this study were selected on the basis of clinical and histologic findings. The lesions of vasculitis were polymorphic. Necrotizing vasculitis typically presented as palpable nonblanching erythematous papules with a tendency to ulcerate. The lesions were located primarily on the lower legs and feet. On routine histologic examination, the walls of the small dermal blood vessels were infiltrated by polymorphonuclear leukocytes. Neutrophils or a mixed pattern of neutrophils and mononuclear cells surrounded the involved vessels. There was evidence of leukocytoclasis (fragmentation of nuclei) in the surrounding tissue. Fibrinoid necrosis of the vessel wall was also apparent. Extravasation of erythrocytes and endothelial cell swelling were often present and hemosiderin deposits were occasionally noted. Subcutaneous nodules and ulcerations were seen in patients with cutaneous periarteritis nodosa and histologic examination of these lesions revealed vasculitis and necrosis of larger, deeper dermal blood vessels.

Most patients with a lymphocytic vasculitis or lymphocytic perivascular infiltrates had clinical lesions typical of erythema multiforme, livedoid vasculitis (atrophie blanche), or acute parapsoriasis. In erythema multiforme the most characteristic histologic finding was a mononuclear perivascular infiltrate. In patients with atrophie blanche there was endothelial cell proliferation with thickening and thrombosis of small dermal vessels. These vessels were surrounded by an infiltrate composed of lymphoid cells and histiocytes. Acute parapsoriasis (Mucha-Habermann) was characterized by a perivascular infiltrate of mononuclear cells with endothelial cell swelling and focal erythrocyte extravasation. The walls of these vessels were often permeated by the infiltrating cells, but neutrophils and leukocytoclasis were not present.

In most cases the etiology of the cutaneous vasculitis could not be determined. Some lesions were thought to represent hypersensitivity reactions to drugs, whereas others were associated with an underlying systemic disorder. Diseases affecting some of the patients with necrotizing vasculitis included rheumatoid arthritis, angioimmunoblastic lymphadenopathy, subacute bacterial endocarditis, Hodgkin's disease, hypereosinophilic syndrome, and cryoglobulinemia.

Sera for immune complex studies were separated from freshly drawn blood and kept frozen at $-70^{\circ} \mathrm{C}$ until use. Sequential serum samples were obtained whenever possible. One full thickness punch biopsy of lesional skin was taken from each patient for histologic study after local anesthesia with $2 \%$ lidocaine. The tissue was fixed in $10 \%$ formalin solution, stained with hematoxylin and eosin, and examined by light microscopy. Early lesions ( $<24 \mathrm{~h}$ old) were biopsied whenever possible.

Direct immunofluorescence. Skin biopsy specimens from early lesions were obtained for direct IF at the time of biopsy for histologic study. Specimens were frozen immediately in liquid nitrogen and stored at $-70^{\circ} \mathrm{C}$ until sectioned. Direct IF staining was performed by methods previously described in detail (21) using monospecific fluorescein-conjugated antisera to IgG, IgM, IgA, C3, and fibrin. Antisera were checked for activity and specificity by immunodiffusion (Ouchterlony) and immunoelectrophoresis. Units of antiserum, antibody protein assays, fluorescein-protein ratios, and dilutions at which these conjugated antisera were used, conformed to previously determined standards (21).

$C 1 q$ binding assay. The $\mathrm{Clq}$ binding assay.was performed by the method of Nydegger et al. (22) with modifications by Tappeiner et al. (23) and Zubler et al. (24). Briefly, Clq was isolated from defibrinated fresh human plasma by the DNA extraction method of Agnello et al. (25), and labeled with ${ }^{125} \mathrm{I}$ in a lactoperoxidase-catalyzed reaction (26).

IgG $(25 \mathrm{mg} / \mathrm{ml})$ was heated at $63^{\circ} \mathrm{C}$ for $12 \mathrm{~min}$ and separated by gel filtration on Sepharose $6 \mathrm{~B}$ in $0.1 \mathrm{M}$ Tris- $\mathrm{HCl}, 0.2 \mathrm{M}$ $\mathrm{NaCl}, \mathrm{pH} 8.5$ (23). Only protein eluting in the exclusion volume was used as heat-aggregated (Agg) IgG.

To assay $\mathrm{Clq}$ binding activity (BA), $0.2-\mathrm{ml}$ aliquots of serum 
sample were diluted in $0.2 \mathrm{ml}$ of $0.26 \mathrm{M}$ EDTA, pH 7.5. To each tube, $0.05 \mathrm{ml}$ of a $5-\mu \mathrm{g} / \mathrm{ml}$ solution of ${ }^{125} \mathrm{I}-\mathrm{Clq}$ was added. After incubation, $3 \mathrm{ml}$ of a solution of polyethylene glycol 6000 was added to make a final concentration of $1.5 \%$ polyethylene glycol. After $2 \mathrm{~h}$ incubation at $4^{\circ} \mathrm{C}$, the tubes were centrifuged, supernates discarded, and the remaining reactivity measured in a gamma scintillation spectrometer (Packard Instrument Co., Inc., Downers Grove, Ill.) and calculated as percent of the total activity added. Results were compared with binding of known concentrations (5-1,000 $\mu \mathrm{g}$ ) of Agg IgG and were expressed as micrograms of Agg IgG equivalents per milliliter. Normal levels of Clq BA were $<5 \mu \mathrm{g}$ Agg IgG eq/ml.

$m R F$ inhibition assay. Two radioassays that use $\mathrm{mRF}$ were performed using methods described by Luthra et al. (27) and Gabriel and Agnello (28). These different assays were performed to test for the possibility that in the solid-phase mRF assay (27), rheumatoid factor present in the patients' sera could bind to ${ }^{125}$ I-labeled Agg IgG resulting in lower counts and false positive test results.

In the solid-phase mRF assay, mRF was separated from the serum of a patient with macroglobulinemia. This serum was dialyzed against $0.1 \mathrm{M}$ glycine $\mathrm{HCl}, \mathrm{pH} 3.0$ buffer for $12 \mathrm{~h}$ at $4^{\circ} \mathrm{C}$, and applied to a Sephadex G-200 column in that buffer. The exclusion protein peak was conjugated with $\mathrm{CnBr}$ to microcrystalline cellulose beads.

IgG Cohn fraction II was aggregated by heating at $63^{\circ} \mathrm{C}$ for $12 \mathrm{~min}$ and was then applied to a sucrose density gradient to obtain aggregates $>25 \mathrm{~S}$. These aggregates were radiolabeled with ${ }^{125} \mathrm{I}$, again in a lactoperoxidase-catalyzed reaction (26).

Tubes containing $0.5 \mathrm{ml}$ serum sample dilution, $0.5 \mathrm{ml}{ }^{125} \mathrm{I}$ Agg IgG dilution $(0.4 \mu \mathrm{g} / \mathrm{ml})$, and $0.5 \mathrm{ml} \mathrm{mRF}$-cellulose dilution were incubated with rotation, centrifuged, washed with buffer, then counted in a gamma scintillation spectrometer. Results were compared with a standard curve of Agg IgG $(0.03-4 \mu \mathrm{g} / \mathrm{ml})$ in normal human serum and expressed as microgram Agg IgG equivalents per milliliter. Levels $>5 \mu \mathrm{g} \mathrm{Agg}$ IgG $\mathrm{eq} / \mathrm{ml}$ were considered abnormal.

In the soluble $\mathrm{mRF}$ assay (28), $\mathrm{mRF}$ was separated as described above and labeled with ${ }^{125} \mathrm{I}$ by the method of Heusser et al. (26). IgG was coupled to Sepharose 6B by the method of Bing (29) using $\mathrm{CnBr}$. After incubation of $0.1 \mathrm{ml}{ }^{125} \mathrm{I}-\mathrm{mRF}$ with $0.01 \mathrm{ml}$ serum sample and buffer $(0.075 \mathrm{M}$ Tris- $\mathrm{HCl}$, $0.01 \mathrm{M} \mathrm{Na}_{2} \mathrm{H}_{2}$ EDTA, $1 \%$ bovine serum albumin, pH 7.4) 0.1 $\mathrm{ml}$ IgG-Sepharose was added. The tubes were then incubated, centrifuged, and washed. The radioactivity of the remaining pellet was counted in a gamma scintillation spectrometer and the results were again expressed as micrograms of Agg IgG equivalents per milliliter after comparison with a standard curve of Agg IgG prepared as described above.

Density gradient ultracentrifugation. Undiluted serum samples of $0.5 \mathrm{ml}$ were layered over a $5-40 \%$ sucrose density gradient in Beckman polyallomer tubes (Beckman Instruments, Inc., Fullerton, Calif.) and centrifuged at $217,500 \mathrm{~g}$ for $15 \mathrm{~h}$ at $4^{\circ} \mathrm{C}$ in a Beckman L5-50 preparative ultracentrifuge with a SW-40TI rotor. The gradient tubes were punctured after centrifugation, and 14 fractions, $\sim 0.65 \mathrm{ml}$ each, were collected.

Gel filtration chromatography. Undiluted serum samples of $1.0 \mathrm{ml}$ each were passed over a column of Sepharose 6B $(2.0 \times 60 \mathrm{~cm}$, downward flow, $0.1 \mathrm{M}$ Tris- $\mathrm{HCl}, 0.2 \mathrm{M} \mathrm{NaCl}$, pH 8.5 buffer at $4^{\circ} \mathrm{C}$ ). Fractions were collected every 2 min with a flow rate of $30 \mathrm{ml} / \mathrm{h}$. Effluents were monitored for protein content by measuring the optical density at $280 \mathrm{~nm}$.

Anticomplementary activity. Anticomplementary activity was assayed by methods previously described (30). Briefly, $0.025-\mathrm{ml}$ aliquots of serum that had been fractionated by either density gradient ultracentrifugation or gel filtration (see above) were diluted $(1: 2-1: 256)$ in a microtiter plate in $0.025 \mathrm{ml}$ dextrose gelatin veronal buffer. Using a dilution just capable of producing $100 \%$ lysis, normal human serum $(0.025 \mathrm{ml})$ was added to each well as a source of complement. After incubation of plates at $30^{\circ} \mathrm{C}$ for $30 \mathrm{~min}, 0.025 \mathrm{ml}$ sensitized sheep cells (EA $1.5 \times 10^{8} / \mathrm{ml}$ ) was added. The plates were then incubated for $1 \mathrm{~h}$ at $37^{\circ} \mathrm{C}$, centrifuged, and read for hemolysis.

Miscellaneous. Protein concentration of density gradient fractions was estimated by the Hartree modification (31) of the Lowry method (32). Cryoproteins were detected by methods previously described (33). Total serum hemolytic complement $\left(\mathrm{CH}_{50}\right)$ was determined by a modification of the method of Shulman (34). Double immunodiffusion (Ouchterlony) was carried out in $0.6 \%$ agarose in veronal-buffered saline, $\mathrm{pH}$ 7.5. Plates were developed at $37^{\circ} \mathrm{C}$ and read after 24 and $48 \mathrm{~h}$. Hepatitis $\mathrm{B}$ surface antigen $\left(\mathrm{HB}_{\mathrm{s}} \mathrm{Ag}\right)$ was assayed by solid-phase radioimmunoassay (Abbott Diagnostics, North Chicago, Ill.).

\section{RESULTS}

84 of the 94 biopsy specimens showed positive direct IF of blood vessels with anti-immunoglobulins, C3, or fibrin. Fig. la demonstrates blood vessel IF after staining for fibrin, a pattern that is characteristic for leukocytoclastic vasculitis. Fig. $1 b$ demonstrates direct IF of blood vessel walls with antiserum to IgM. Specimens from 45 of 54 patients with leukocytoclastic vasculitis showed vessel immunoglobulin or complement deposits, and 26 of 40 patients with lymphocytic vasculitis or a lymphocytic perivascular infiltrate demonstrated similar findings.

A combination of deposits of IgM, C3, and fibrin was detected in 24 of the 94 specimens. IgA was found in 15 biopsies and IgG in only 3, all from patients in the leukocytoclastic vasculitis group.

Specimens from three patients with Henoch-Schöenlein purpura demonstrated IgA deposition in blood vessels, a finding previously described in such patients (35). In this disease various combinations of cutaneous vasculitis with signs of systemic vasculitis, including arthritis, abdominal pain, melena, and hematuria are frequently seen. Two of our patients were children who developed a purpuric eruption, fever, arthralgias, and abdominal pain or nausea after a sore throat. One child later developed glomerulonephritis. The third patient, an adult, had four episodes of a purpuric rash associated with arthritis, abdominal pain, and melena.

Cryoglobulins and depression of total complement. 70 serum samples were tested for the presence of cryoglobulins. Cryoglobulins were detected in 15 of 52 patients with leukocytoclastic vasculitis but in only 2 of 18 patients with lymphocytic vasculitis or a lymphocytic perivascular infiltrate.

14 of 72 patients tested had depressed $\mathrm{CH}_{50}$ levels. All of these patients had leukocytoclastic vasculitis. Of the 17 patients with measurable cryoglobulins, 6 also had low $\mathrm{CH}_{50}$. 


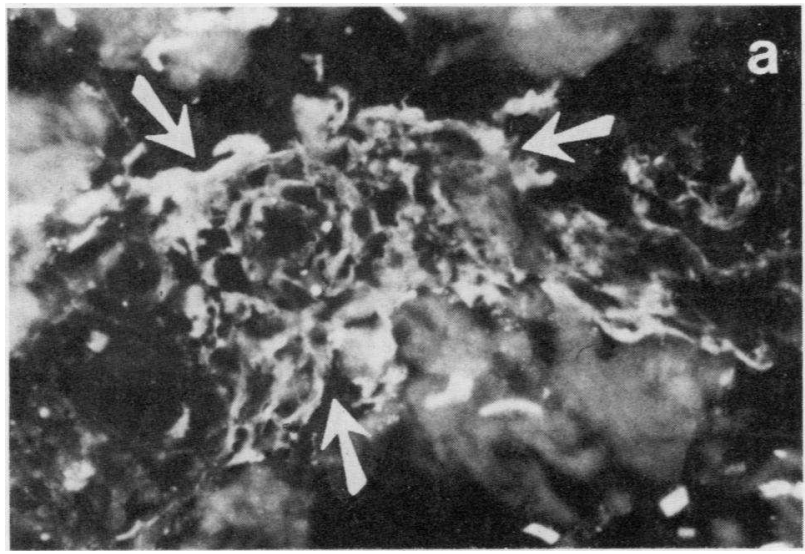

Figure 1 (a) Direct IF with fluorescein-conjugated antifibrin demonstrating diffuse IF in and around cutaneous blood vessel. $\times 400$. (b) Superficial cutaneous blood vessels demonstrating IgM in vessel walls (arrows). $\times 250$.

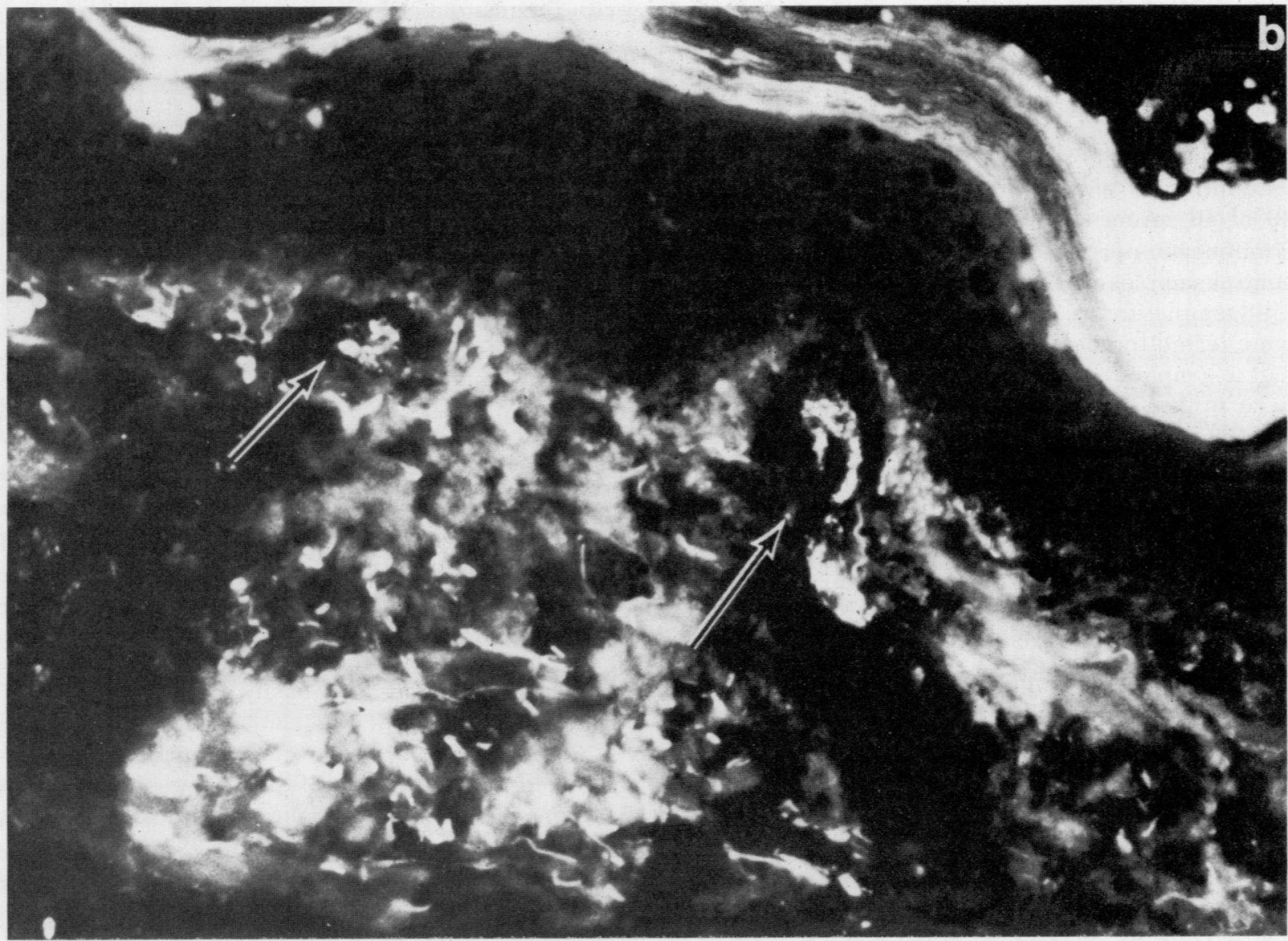

C1q binding assay. Serum samples from 107 patients with cutaneous vasculitis were tested for the presence of circulating immune complexes by the $\mathrm{Clq}$ binding assay. A total of 36 patients $(34 \%)$ had sera reactive with Clq. 32 of 59 patients $(54 \%)$ in the leukocytoclastic vasculitis group but only 4 of $48(9 \%)$ in the lymphocytic-perivascular group demonstrated elevated Clq BA (Fig. 2). 19 patients with leukocytoclastic vasculitis demonstrated markedly elevated levels of
Clq BA, whereas only 1 patient in the lymphocyticperivascular group showed Clq BA significantly elevated from normal. Of the 26 patients with erythema multiforme, samples from only 2 were reactive with Clq. These patients had levels of Clq BA of 6 and 12 $\mu \mathrm{g}$ Agg IgG eq/ml. None of the 150 control samples had elevated Clq BA.

$m R F$ assays. The solid-phase $\mathrm{mRF}$ assay (27) was positive in 49 of 101 (49\%) serum samples tested. 30 of 


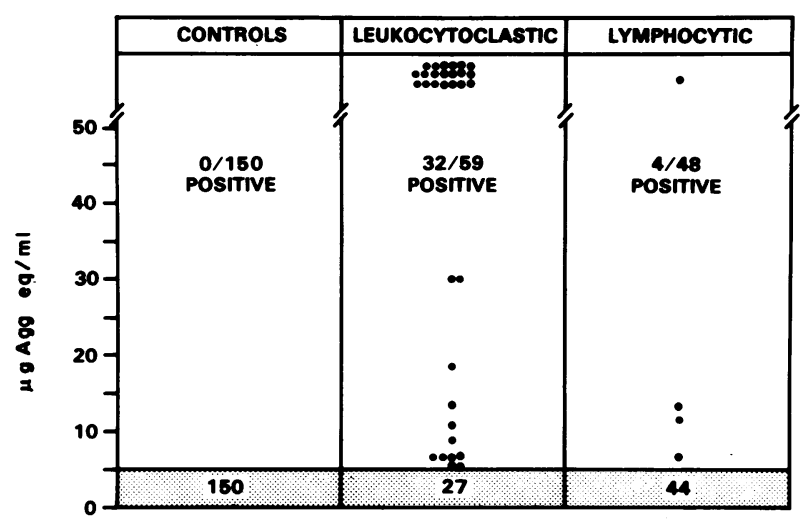

FIGURE 2 Scattergram demonstrating Clq reactivity in serum samples from patients with leukocytoclastic vasculitis and lymphocytic vasculitis or a perivascular lymphocytic infiltrate and in normal control sera. Serum samples with normal levels of Clq BA ( $\leq 5 \mu \mathrm{g} \mathrm{Agg} \mathrm{IgG} \mathrm{eq/ml)} \mathrm{are} \mathrm{included} \mathrm{in} \mathrm{the} \mathrm{hatched}$ areas.

55 samples (55\%) from patients with leukocytoclastic vasculitis had elevated levels (Fig. 3). Interestingly, 19 of 46 serum samples (41\%) from patients in the lymphocytic-perivascular group also were positive. 35 control samples were negative.

38 samples from 23 patients with cutaneous vasculitis were tested by the soluble $\mathrm{mRF}$ assay (28). 9 patients had a lymphocytic vasculitis or lymphocytic perivascular infiltrate and 14 had leukocytoclastic vasculitis. These results were compared with those obtained with the solid-phase mRF assay (27). There was agreement in 35 of the samples tested. Three samples were positive by the solid-phase $\mathrm{mRF}$ assay but negative by the soluble mRF assay, and only one of these cases showed a significant difference in the level of mRF BA. In one case, increased binding was detected by the solu-

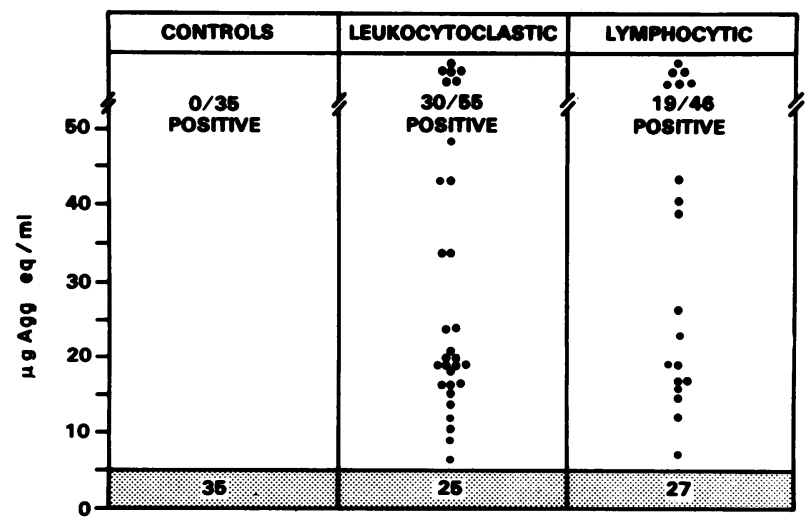

FIGURE 3 Scattergram demonstrating $m R F$ reactivity in serum samples from patients with leukocytoclastic vasculitis and lymphocytic vasculitis or a perivascular lymphocytic infiltrate and in normal control sera. Serum samples with normal levels of $\mathrm{mRF}$ reactive material ( $\leq 5 \mu \mathrm{g} \mathrm{Agg} \mathrm{IgG} \mathrm{eq} / \mathrm{ml}$ ) are included in the hatched areas. ble mRF assay alone, but only at a minimally elevated level. 11 of the 13 patients tested for the presence of rheumatoid factor (RF) were negative and 2 were positive. In one of these two patients there was disagreement in the results obtained with the two $\mathrm{mRF}$ radioassays. BA was detected with the solid-phase $\mathrm{mRF}$ assay, whereas the soluble $\mathrm{mRF}$ assay was within normal limits. Because only a small number of RF-positive patients were tested by both $\mathrm{mRF}$ assays, it could not be determined whether RF that is present in a patient's serum could bind to the Agg IgG in the solid-phase $\mathrm{mRF}$ assay and give a false positive result. However, a comparative study done previously in this laboratory (unpublished data) demonstrated good correlation between these two assays when used in testing patients with rheumatoid arthritis.

Serial blood samples obtained from several patients with necrotizing vasculitis showed a rough correlation between the level of $\mathrm{Clq} B A$ or $\mathrm{mRF}$ reactive material and severity of disease. In one patient, a subsequent onset of hematuria was associated with a marked rise in $\mathrm{mRF}$ reactive material and a slight elevation of $\mathrm{Clq}$ BA. In another patient who had two episodes of palpable purpura within 2 mo a delayed rise in Clq BA and $\mathrm{mRF}$ reactive material was seen during each episode. Usually a lag of 5-7d between onset of clinical disease and detection of circulating immune complexes was noted. Peak levels of $\mathrm{Clq} B A$ and $\mathrm{mRF}$ reactive material were most often detected when the skin lesions were clearing and no new lesions were apparent.

Characterization studies. Normal sera and sera from eight patients with leukocytoclastic vasculitis, one patient with a lymphocytic vasculitis, and three patients with erythema multiforme were selected for study by density gradient ultracentrifugation and gel filtration chromatography.

Fig. 4 summarizes the results of studies performed on fractions obtained by density gradient ultracentrifugation in a representative patient with leukocytoclastic vasculitis (F.R.). The protein content of each fraction collected is shown as a solid line with IgM and IgG markers as indicated. Immune complexlike material was detected in fractions 1,2 , and 3 by both the Clq binding assay (hatched area) and the solid-phase $\mathrm{mRF}$ assay (broken line). Anticomplementary activity was present at a dilution of 1:64 in fraction 1 and at 1:128 in fractions 2-5.

Solid-phase radioimmunoassay for $\mathrm{HB}_{\mathrm{s}} \mathrm{Ag}$ was performed on density gradient fractions of patient F.R. who had $\mathrm{HB}_{\mathrm{s}} \mathrm{Ag}$-positive hepatitis in addition to vasculitis. $\mathrm{HB}_{\mathrm{s}} \mathrm{Ag}$ was found in high levels in the heavy gradient fractions (Fig. 4) when compared with later gradient fractions.

Fig. 5 summarizes the results of studies performed on fractions collected after gel filtration of serum from E.W., a patient with rheumatoid arthritis, leukocyto- 


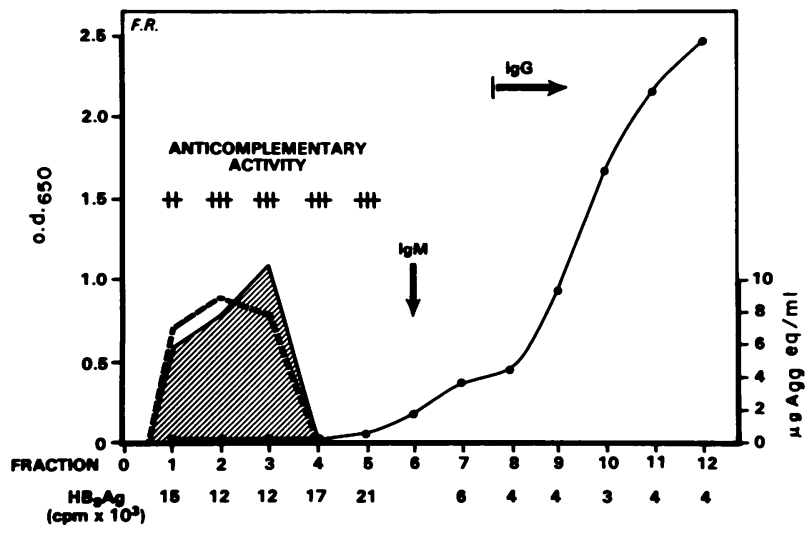

FIgURE 4 Sucrose density gradient ultracentrifugation of serum from patient F.R. Protein content is shown (O) with IgM (19S) and IgG (7S) markers. Anticomplementary activity $(\#, \ldots)$ was detected in fractions 1-5. The hatched area represents fractions containing Clq reactivity. $\mathrm{mRF}$ reactive fractions are indicated by a broken line. $\mathrm{HB}_{\mathrm{s}} \mathrm{Ag}$ content as measured by radioimmunoassay is shown.

clastic vasculitis, and cryoglobulinemia. The optical density $(280 \mathrm{~nm})$ of each fraction is shown as well as the location of IgM and IgG markers. Reactivity with Clq was located in fractions 52-56 (hatched area), and the solid-phase mRF assay was positive in fractions 52-55 (broken line). Anticomplementary activity was present in fractions 56-57 at dilutions of $1: 32$ and $1: 64$, respectively.

Anticomplementary activity was detected in the heavy molecular weight fractions obtained from five other patients with necrotizing vasculitis, and reactivity with $\mathrm{Clq}$ and $\mathrm{mRF}$ was demonstrated in these same fractions in four patients. The serum of one patient with necrotizing vasculitis had high levels of $\mathrm{mRF}$ reactive material but no Clq BA. By sucrose density gradient ultracentrifugation, $\mathrm{mRF}$ reactive material in this serum eluted in somewhat lighter fractions (fractions $10,11$, and 12$) \sim 8-10 \mathrm{~S}$ in size. Only $\mathrm{mRF}$ reactive material, however, was detected in heavy molecular weight fractions (19S or greater) in the patients with lymphocytic vasculitis and in one of the three patients with erythema multiforme.

Normal sera, in addition to pathologic sera, consistently showed anticomplementary activity at a $1: 16$ dilution in sucrose density gradient fractions 6 and 7 , a phenomenon not well understood. Early fractions of control sera, however, were always negative for anticomplementary activity. All fractions of normal sera were negative for both $\mathrm{Clq}$ and $\mathrm{mRF}$ reactive material. No Clq or $\mathrm{mRF}$ binding reactivity or anticomplementary activity was present in fractions obtained from gel filtration of normal sera.

By using double immunodiffusion, precipitin band reactions against $m R F$ and $C l q$ could be demonstrated against gel filtration fractions containing $\mathrm{Clq}$ and $\mathrm{mRF}$ reactive material with anticomplementary activity (Fig. $6 a$ and $b$ ). In fractions obtained by density gradient ultracentrifugation, only precipitin bands against $\mathrm{mRF}$ could be demonstrated. IgM and, occasionally, IgG were detected by double immunodiffusion in heavy molecular weight anticomplementary fractions.

\section{DISCUSSION}

Leukocytoclastic vasculitis has long been considered a cutaneous form of immune complex disease $(13,16$, 20 ). The studies reported herein support this contention as circulating immune complexes were detected in 32 of 59 serum samples $(54 \%)$ using the Clq binding assay and in 30 of $55(55 \%)$ tested by the mRF solidphase radioassay. 22 of the serum samples had immune complexes detectable by both assays. Thus, in leukocytoclastic vasculitis, not only is there considerable indirect evidence, such as a histologic similarity of the cutaneous lesions to the Arthus reaction and IF evidence of immunoglobulin and complement deposition in affected blood vessels, but also direct evidence by the demonstration of anticomplementary material in the circulation of these patients that is reactive with both $\mathrm{Clq}$ and $\mathrm{mRF}$. In addition, both density gradient and gel filtration studies of most sera suggest that the $\mathrm{Clq}$ and $\mathrm{mRF}$ binding material in these patients is $>19$ S, a size consistent with antigen-antibody complexes (36).

There was no significant difference in the incidence of positive direct IF in the various subgroups of patients (rheumatoid arthritis, cryoglobulinemia, drug reactions, and systemic disease) with necrotizing vasculitis. However, Clq reactive material was detected in a greater frequency than $m R F$ reactive material in

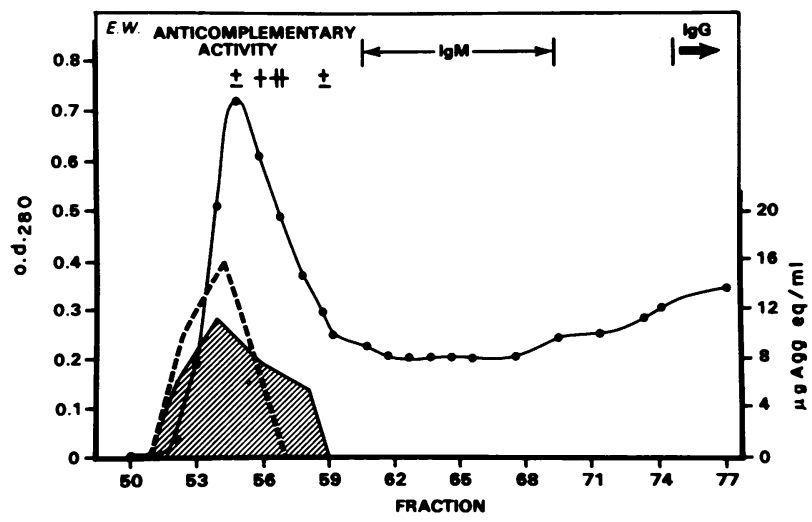

Figure 5 Sepharose 6B gel chromatography of serum from patient E.W. Protein content is shown (O) with IgM (19S) and IgG (7S) markers. Anticomplementary activity $( \pm, H+H, \pm$ ) was detected in fractions 55-59. The hatched area represents fractions containing $\mathrm{Clq}$ reactivity. $\mathrm{mRF}$ reactive fractions are indicated by a broken line. 

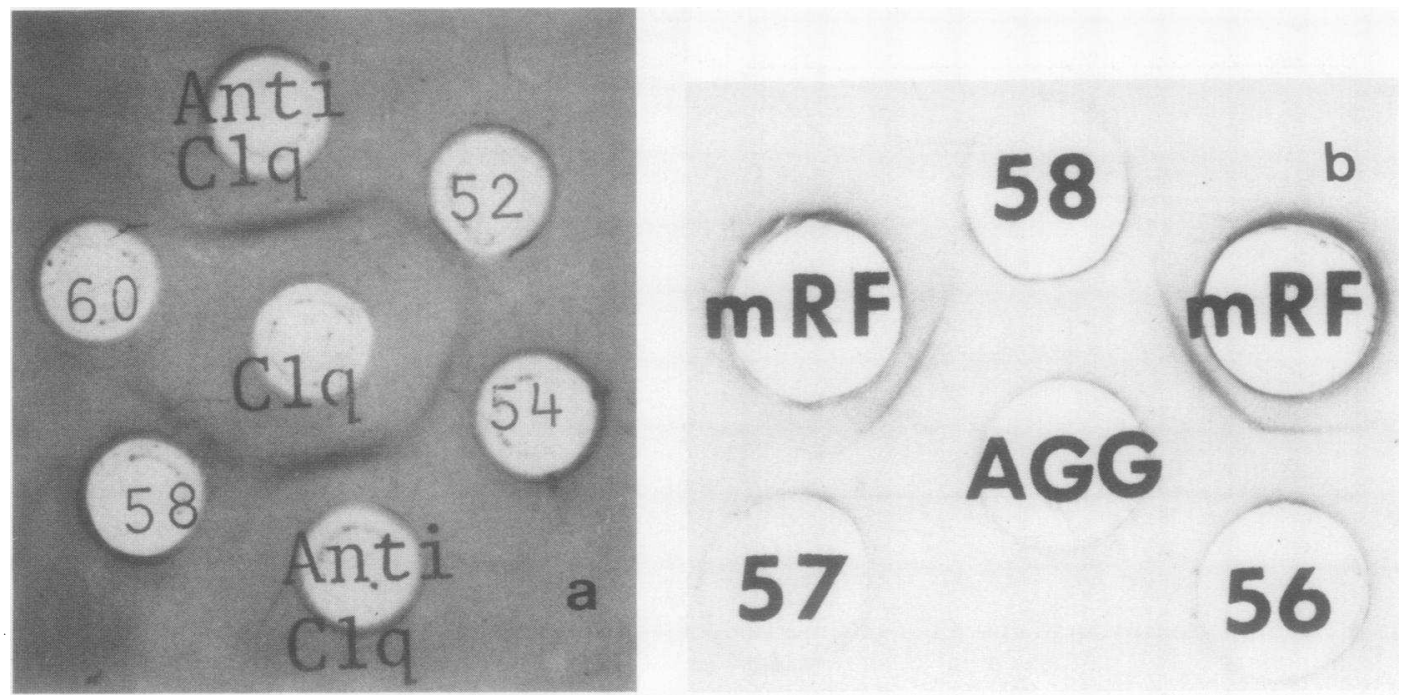

FIGURE 6 (a) Gel diffusion showing precipitin bands against Clq in Sepharose 6B fractions (E.W.) 52, 54, and 58. (b) Gel diffusion demonstrating precipitin bands with $\mathrm{mRF}$ and Sepharose $6 B$ fractions (E.W.) 56 and 57.

the sera of patients with both rheumatoid arthritis and cryoglobulinemia. In contrast, $\mathrm{mRF}$ reactive material was detected more often than $\mathrm{Clq}$ reactive material in the idiopathic and drug-related groups. In the patients with an underlying disease such as carcinoma, hepatitis, etc., the Clq and mRF assays were positive in equal frequency.

At least some forms of lymphocytic vasculitis and diseases exhibiting lymphocytic perivascular infiltrates may be immune complex-mediated because $41 \%$ of the serum samples had elevated levels when tested by the mRF assay. Interestingly, only 4 of 48 of these samples showed elevated Clq BA; 3 of these sera were minimally elevated. The ability of an immune complex to activate complement and presumably to interact with $\mathrm{Clq}$ is dependent upon its size $(29,37)$. Preliminary data from this laboratory using Agg IgG indicates that both the Clq and mRF assays can detect complexes $>19 \mathrm{~S}$ as well as complexes of intermediate size. The $\mathrm{mRF}$ assay does appear to be the more sensitive of the two tests for detection of lighter (7-19S) complexes, whereas the Clq assay is more sensitive in detecting complexes $>19 S$. Separation studies of serum from Clq-negative mRF-positive patients revealed the presence of light $\mathrm{mRF}$ reactive material in some and heavy $m R F$ reactive material in others. Thus, the absence of Clq BA in the sera of these patients must be explained by more than the size of the immune complex alone.

In a recently published collaborative study comparing multiple methods for immune complex detection, 17 patients with leukocytoclastic vasculitis were included (38). $76 \%$ of these sera were reactive by the $\mathrm{Clq}$ binding assay and $50 \%$ were reactive using the solid-phase $\mathrm{mRF}$ assay (27). Our $\mathrm{mRF}$ data $(55 \%$ reactivity) shows close correlation with this study. Although we detected $\mathrm{Clq}$ reactive material in a lower frequency ( $54 \%$ reactivity), our data is in general agreement with World Health Organization (WHO) results. Interestingly, the soluble $\mathrm{mRF}$ assay (28) was less sensitive ( 35 vs. $50 \%$ ) in detecting immune complexes in vasculitis in the WHO study when compared with the solid-phase $\mathrm{mRF}$ assay (27). In testing a small series of our patients with leukocytoclastic vasculitis, however, both $\mathrm{mRF}$ assays appeared to be equally sensitive.

Blood vessel IF was detected in $89 \%$ of the biopsy specimens. Direct IF was positive in approximately equal frequency in the two groups of patients (group $1,91 \%$ and group $2,88 \%$ ). The severity of the reaction and the age of the lesion may be contributing factors in the frequency of detection of blood vessel IF. Our data suggest that direct IF cannot be used to predict the presence or absence of circulating immune complexes in patients with leukocytoclastic vasculitis, lymphocytic vasculitis, or patients with a lymphocytic perivascular infiltrate.

Total hemolytic complement was depressed in 14 of the 71 cutaneous vasculitis patients tested; all but 2 of these patients had vasculitis of the leukocytoclastic type. Cryoglobulins were detected in 17 of 70 patients tested $(24 \%) ; 15$ of these patients had a leukocytoclastic type of vasculitis. In all but three cases the presence of either a depressed $\mathrm{CH}_{50}$ or cryoglobulinemia was associated with detectable circulating immune complexes. The sera of 11 patients with cryoglobulinemia and 9 patients with depressed $\mathrm{CH}_{50}$ contained both $\mathrm{Clq}$ and $\mathrm{mRF}$ reactive material. Three patients with cryoglobulinemia and four patients with depressed 
$\mathrm{CH}_{50}$ had only $\mathrm{Clq}$ reactive material. No patient with $\mathrm{CH}_{50}$ and only one patient with cryoglobulinemia had circulating immune complexes detectable by only the $\mathrm{mRF}$ assay.

By using density gradient ultracentrifugation and gel filtration chromatography, the $\mathrm{Clq}$ and $\mathrm{mRF}$ reactive material and the anticomplementary material of most sera eluted in high molecular weight fractions, a size consistent with antigen-antibody complexes. In addition, in one case, we were able to identify a two- to threefold elevation of $\mathrm{HB}_{\mathrm{s}} \mathrm{Ag}$ in these same high molecular weight fractions by radioassay when compared with the other fractions. Others have identified $\mathrm{HB}_{\mathrm{s}} \mathrm{Ag}$ in cryoprecipitates (39-41), and in cutaneous blood vessels (39) by direct IF in patients with leukocytoclastic vasculitis. To our knowledge, this is the first time this antigen has been located in high molecular weight fractions, or those that should contain immune complexes. Unfortunately, antigen identification in various forms of cutaneous vasculitis is complicated by the multiplicity of antigens that may play a role in the pathogenesis of this disease. Further studies of this type, i.e., identifying responsible antigens, however, are currently underway.

In 1976 Sams and co-workers (1) proposed a hypothetical model for the development of lesions of leukocytoclastic vasculitis. This was based upon the deposition of soluble immune complexes in blood vessel walls, subsequent activation of complement with release of neutrophil chemotactic factors, fixation of neutrophils to sites of immune complex deposition, and resulting immunologic injury from the release of lysosomal enzymes. The demonstration of circulating immune complexes in a high percentage of patients with active disease adds further support to their contention that leukocytoclastic vasculitis is indeed an immune complex disease. Questions such as the antigen involved, the role of the reticuloendothelial system in handling immune complexes, and the importance of the complement system in mediating vessel destruction remain to be answered. In addition, the early changes taking place that mediate the deposition of immune complexes in blood vessel walls remain unclear. The importance of using more than one type of assay for the detection of circulating immune complexes has also been further substantiated.

\section{ACKNOWLEDGMENTS}

Mrs. Jane Kahl provided excellent technical assistance.

This work was supported in part by research grant AI14550 from the National Institutes of Health, U. S. Public Health Service, and by the Medical Research Service of the Veterans Administration.

\section{REFERENCES}

1. Sams, W. M., Jr., E. G. Thorne, P. Small, M. F. Mass, R. M. McIntosh, and R. E. Stanford. 1976. Leukocytoclastic vasculitis. Arch. Dermatol. 112: 219-226.
2. Gilliam, J. N., and J. D. Smiley. 1976. Cutaneous necrotizing vasculitis and related disorders. Ann. Allergy. 37: 328-339.

3. Copeman, P. W. M., and T. J. Ryan. 1970. The problem of classification of cutaneous angiitis with reference to histopathology and pathogenesis. Br. J. Dermatol. 82: 2-14.

4. Winkelman, R. K., and W. B. Ditto. 1964. Cutaneous and visceral syndromes of necrotizing "allergic" vasculitis. A study of 38 cases. Medicine (Baltimore). 43: 59-89.

5. Goltz, R. W. 1962. Cutaneous manifestations of allergic angiitis. Lancet I. 82: 218-222.

6. Miescher, P. A., F. Paronetto, and D. Koffler. 1965. Immunofluorescent studies in human vasculitis. In Immunopathology IVth International Symposium. P. Grabar, R. A. Miescher, editors. Grune \& Stratton, Inc., New York. 446-456.

7. Dixon, F. J., J. J. Vazquez, W. O. Weigle, and C. G. Cochrane. 1958. Pathogenesis of serum sickness. Arch. Pathol. 65: 18-28.

8. Schroeter, A. L., P. W. M. Copeman, R. E. Jordon, W. M. Sams, and R. K. Winkelman. 1971. Immunofluorescence of cutaneous vasculitis as sociated with systemic disease. Arch. Dermatol. 104: 254-259.

9. Stringa, S. G., C. Bianchi, A. M. Casala, and O. Bianchi. 1967. Allergic vasculitis Gougerot-Ruiter syndrome. Arch. Dermatol. 95: 23-27.

10. Handel, D. W., H. H. Roenigk, J. Shainoff, and S. Deodhar. 1975. Necrotizing vasculitis. Etiologic aspects of immunology and coagulopathy. Arch. Dermatol. 111: 847852.

11. Sams, W. M., H. N. Claman, P. F. Kohler, R. M. McIntosh, P. Small, and M. F. Mass. 1975. Human necrotizing vasculitis: immunoglobulins and complement in vessel walls of cutaneous lesions and normal skin. J. Invest. Dermatol. 64: 441-445.

12. Cream, J. J. 1973. Anticomplementary sera in cutaneous vasculitis. Br. J. Dermatol. 89: 555-559.

13. Cream, J. J. 1976. Clinical and immunological aspects of cutaneous vasculitis. Q. J. Med. (Oxford). N. S. XLV. 178: 255-276.

14. Andrews, B. S., G. Cains, J. McIntosh, V. Petts, and R. Perry. 1979. Circulating and tissue immune complexes in cutaneous vasculitis. J. Clin. Lab. Immunol. 1: 311-320.

15. Soter, N. A., K. F. Austen, and I. Gigli. 1974. The complement system in necrotizing angiitis of the skin. Analysis of complement component activities in serum of patients with concomitant collagen-vascular diseases. $J$. Invest. Dermatol. 63: 219-226.

16. McDuffie, F. C., W. M. Sams, Jr., J. E. Maldonado, P. H. Andreini, D. L. Conn, and E. A. Samayoa. 1973. Hypocomplementemia with cutaneous vasculitis and arthritis. Possible immune complex syndrome. Mayo Clin. Proc. 48: $340-348$.

17. Soter, N. A., K. F. Austen, and I. Gigli. 1974. Urticarias and arthralgias as manifestations of necrotizing angiitis (vasculitis). J. Invest. Dermatol. 63: 485-490.

18. Soter, N. A., M. C. Mihm, I. Gigli, H. F. Dvorak, and K. R. Austen. 1976. Two distinct cellular patterns in cutaneous necrotizing angiitis. J. Invest. Dermatol. 66: 344-350.

19. Soter, N. A. 1976. Clinical presentations and mechanisms of necrotizing angiitis of the skin. J. Invest. Dermatol. 67: $354-359$.

20. Braverman, I. M., and A. Yen. 1975. Demonstration of immune complexes in spontaneous and histamineinduced lesions and in normal skin of patients with leukocytoclastic angiitis. J. Invest. Dermatol. 64: 105-112.

21. Beutner, E. H., T. P. Chorzelski, and R. E. Jordon. 1970. Autosensitization in pemphigus and bullous pemphigoid. (Monograph). Charles C Thomas, Publisher, Springfield, Ill. 194. 
22. Nydegger, U. E., P. H. Lambert, H. Gerber, and P. A. Meischer. 1974. Circulating immune complexes in the serum in systemic lupus erythematosus and in carriers of hepatitis B antigen. Quantitation by binding to radiolabeled Clq. J. Clin. Invest. 54: 297-309.

23. Tappeiner, G., K. G. Heine, J. C. Kahl, and R. E. Jordon. 1977. Clq binding substances in pemphigus and bullous pemphigoid: detection with a ${ }^{[131]}$ I-Clq binding assay. Clin. Exp. Immunol. 28: 40-48.

24. Zubler, R. H., G. Lange, P. H. Lambert, and P. A. Miescher. 1976. Detection of immune complexes in unheated sera by a modified ${ }^{125} \mathrm{I}-\mathrm{Clq}$ binding test. Effect of heating on the binding of Clq by immune complexes and application of the test to systemic lupus erythematosus. $J$. Immunol. 116: 232-235.

25. Agnello, V., R. J. Winchester, and H. G. Kunkel. 1970. Precipitation reactions of the Clq component of complement with aggregated gamma globulins and immune complexes in gel diffusion. Immunology. 19: 909-919.

26. Heusser, C., M. Boesman, J. H. Nordin, and H. Isiker. 1973. Effect of chemical and enzymatic radioiodination on in vitro human Clq activities. J. Immunol. 110: $820-828$.

27. Luthra, H. S., F. C. McDuffie, G. G. Hunder, and E. A. Samayoa. 1975. Immune complexes in sera and synovial fluids of patients with rheumatoid arthritis.J. Clin. Invest. 56: 458-466.

28. Gabriel, A., Jr., and V. Agnello. 1977. Detection of immune complexes. The use of radioimmunoassays with Clq and monoclonal rheumatoid factor. J. Clin. Invest. 59: $990-1001$.

29. Bing, D. H. 1974. Purification of the first component of human complement and its subunit $\mathrm{Cl}$ esterase. Methods Enzymol. 34: 731-746.

30. Jordon, R. E., and F. C. McDuffie. 1976. Serum and blister fluid anticomplementary activity in pemphigus and bullous pemphigoid. Sucrose density gradient studies. Proc. Soc. Exp. Biol. Med. 151: 594-598.

31. Hartree, E. F. 1972. Determination of protein: a modifica- tion of the Lowry method that gives a linear photometric response. Anal. Biochem. 48: 422-427.

32. Lowry, O. H., N. J. Rosebrough, A. L. Farr, and R. J. Randall. 1951. Protein measurement with the Folin phenol reagent. J. Biol. Chem. 193: 265-275.

33. Barnett, E. V., R. Bluestone, A. Cracchiolo, K. S. Goldberg, C. L. Kantor, and R. M. McIntosh. 1970. Cryoglobulinemia and disease. Ann. Intern. Med. 73: 95- 107.

34. Shulman, N. R. 1958. Immunoreactants involving platelets. J. Exp. Med. 107: 665-690.

35. Giangiacomo, J., C. C. Tsai. 1977. Dermal and glomerular deposition of IgA in anaphylactoid purpura. Am. J. Dis. Child. 131: 981-983.

36. Cochrane, C. G. 1971. Mechanisms involved in the deposition of immune complexes in tissues. J. Exp. Med. 134: $75-89$.

37. Lightfoot, R. W., R. E. Drusin, and C. L. Christian. 1970. Properties of soluble immune complexes. J. Immunol. 105: 1493-1500.

38. Lambert, P. H., F. J. Dixon, R. H. Zubler, V. Agnello, C. Cambiaso, P. Casali, J. Clarke, J. S. Cowdery, F. C. McDuffie, F. C. Hay, I. C. M. MacLennan, P. Masson, H. J. Müller-Eberhard, K. Penttinen, M. Smith, G. Tappeiner, A. N. Theofilopoulos, and P. Verroust. 1978. A WHO collaborative study for the evaluation of eighteen methods for detecting immune complexes in serum. $J$. Clin. Lab. Immunol. 1: 1-15.

39. Thorne, E. G., R. Gower, and H. N. Claman. 1977. Hepatitis B surface antigen and leukocytoclastic vasculitis. J. Invest. Dermatol. 68: 243. (Abstr.)

40. Levo, Y., P. D. Gorevic, H. J. Kassab, D. Zucker-Franklin, and E. C. Franklin. 1977. Association between hepatitis $B$ virus and essential mixed cryoglobulinemia. $N$. Engl. J. Med. 296: 1501-1504.

41. Wands, J. R., E. Mann, E. Alpert, and K. J. Isselbacher. 1975. The pathogenesis of arthritis associated with acute hepatitis-B surface antigen-positive hepatitis. J. Clin. Invest. 55: 930-936. 